\title{
Purification characteristics of golden pothos for emitting air-pollutants from plywood using a gas sensor
}

\author{
T. Oyabu ${ }^{1}$, T. Onodera ${ }^{2}$, A. Sawada ${ }^{1} \&$ M. Tani ${ }^{1}$ \\ ${ }^{1}$ Graduate School of Regional Economic Systems, \\ Kanazawa Seiryo University, Japan \\ ${ }^{2}$ Graduate School of Information Science and Electrical Engineering, \\ Kyushu University, Japan
}

\begin{abstract}
Sick-house syndrome widely occurs in general domiciles. Its cause is from various types of chemical substances generated from building materials. The airtight structure is also one of the main causes for the syndrome. The most prevalent chemicals are formaldehyde, toluene and xylene. It is well known that plants have purification capabilities for these chemicals in an indoor environment. It is strongly desired to reduce the pollution level for multiple chemical sensitivity in domiciles and buildings. Foliage plants are very effective in reducing the pollution concentration. In this study, the purification characteristics of golden pothos for polluting chemicals emitting from a piece of building board are examined using a tin oxide gas sensor. The experiments are carried out in an airtight chamber of 200 liters. The number of plant pots were also changed from 0 to 3 in the experiments. As for the results, pothos had high purification capabilities for those chemicals and the capabilities increased as the number of pots were added. The purification rate reached almost $100 \%$ at over three pots in the chamber experiment. The approximate function of the purification characteristic is derived using an exponential function. The system can introduce the pollution level in an indoor environment using this expression. It is felt that this model can be effective in estimating the pollution level and the design of an indoor environment.
\end{abstract}

Keywords: foliage plant, air-pollutant, purification, formaldehyde, gas sensor. 


\section{Introduction}

Various kinds of chemical substances are used in an indoor environment and these chemicals have occurred in human surroundings. Therefore, some residents fall into multiple chemical sensitivity (MCS) and sick-house syndrome, and they can not be fit for their daily life due to these diseases. The Ministry of Land, Infrastructure and Transport of Japan suggested that housing companies should measure the pollution levels of formaldehyde, toluene, xylene, ethyl-benzene and styrene in a built residence and publish the results officially. It has been reported that plants have a capability to remove atmospheric pollution [1-4]. In these studies, it was reported that a potted plant was put in an experimental chamber and a polluting chemical was injected into the chamber and the concentration of the chemical decreased with the passage of time. Various kinds of plants have capabilities to purify many kinds of atmospheric pollutants[5][6]. In a real domicile, the pollutants, however, generate continuously, and the generating volume increases as the atmospheric concentration of the pollutant decreases. We looked at how much the purification capability of the plants in those environments and measured the purification characteristics of the plants using a tin oxide gas sensor.

In this study, a piece of plywood was put in the chamber together with potted plants and the characteristics of polluting level were measured. The number of potted plants required to obtain a clean environment, was derived by a computer simulation. It became obvious that over three potted plants are required in the experimental environment of this study. The results can be practicable in domiciles and buildings.

\section{Experimental}

Experiments were carried out in a thermo-hygrostat room (Tabai: TBR 5HA2G3A). An experimental chamber of 200 liters was installed in the room. A piece of plywood (JAS (Japanese Agricultural Standard): F2, 300×300×9mm) and potted pothos were put in the chamber. The temperature and humidity in the thermo-hygrostat room were controlled at 22 degree centigrade and $60 \% \mathrm{RH}$. The sunlight was isolated in the experimental room and the light intensity was controlled at 730 lux using fluorescent lights. The temperature in the chamber was about 22 degree centigrade and the humidity was over $75 \%$ RH. The humidity was strongly influenced by plant-biorhythm. The experimental system is shown in Fig.1. It was always agitated in the chamber by a fan. The plywood and potted plants were put together in the chamber. The number of pots was increased to three. These pots were the same size $(15 \mathrm{~cm}$ in diameter and $17 \mathrm{~cm}$ in height) and the plants were also about same size. A photograph of these pots is shown in Fig.2. The formaldehyde concentration in the chamber was measured using a tin oxide gas sensor (Figaro TGS\#860). The sensor is named AMS in this paper. The real concentration was derived using a measuring instrument (RIKEN CO., FR-85) and the data were corrected using the relationships. 
This type of gas sensor has been used to detect various types of atmospheric pollutants $[7,8]$. The tin oxide gas sensor is one of the more popular sensors and is available on the market now. The sensor has a high reliability and costperformance. The sensor, which was used in this experiment, was developed to detect ammonia gas selectively. It does not have high gas-selectivity. The sensor and a load resister $\left(R_{L}\right)$ were connected in series and dc voltage $\left(V_{c}\right)$ was applied to the circuit. The voltage of both the ends of the load resistance was introduced as the sensor output $\left(V_{\text {out }}\right) . V_{\text {out }}=R_{L} V_{c} /\left(R_{s}+R_{L}\right)$, where $R_{s}$ means sensor resistance. The surface of the sensor element is usually covered with oxygen and hydroxide molecules. The molecules cover the sensor surface with binding free electrons inside sensor bulk. For example, when methyl alcohol gas comes near the sensor surface, the following reactions (eq.(1) and (2)) occurred, and aldehyde $\left(\mathrm{CH}_{3} \mathrm{CHO}\right)$ or ethoxy $\left(\mathrm{C}_{2} \mathrm{H}_{5} \mathrm{O}\right)$ were generated. As for the results, conduction electrons return into the sensor-bulk, and the sensor resistance $R_{s}$ decreases and $V_{\text {out }}$ increases. Namely, when the concentration of a reducing gas in the atmosphere increases, $R_{s}$ decreases and output $V_{\text {out }}$ increases, and $V_{\text {out }}$ come up to $V_{c}$ level. A photograph of the sensor used in this experiment is shown in Fig.3. The output voltage was inputted every minute through an A/D converter.

$$
\begin{gathered}
\mathrm{C}_{2} \mathrm{H}_{5} \mathrm{OH}+\mathrm{O}^{-} \rightarrow \mathrm{CH}_{3} \mathrm{CHO}+\mathrm{H}_{2} \mathrm{O}+e \\
\mathrm{C}_{2} \mathrm{H}_{5} \mathrm{OH}+\mathrm{O}^{-} \rightarrow \mathrm{C}_{2} \mathrm{H}_{5} \mathrm{O}+\mathrm{OH}+e
\end{gathered}
$$

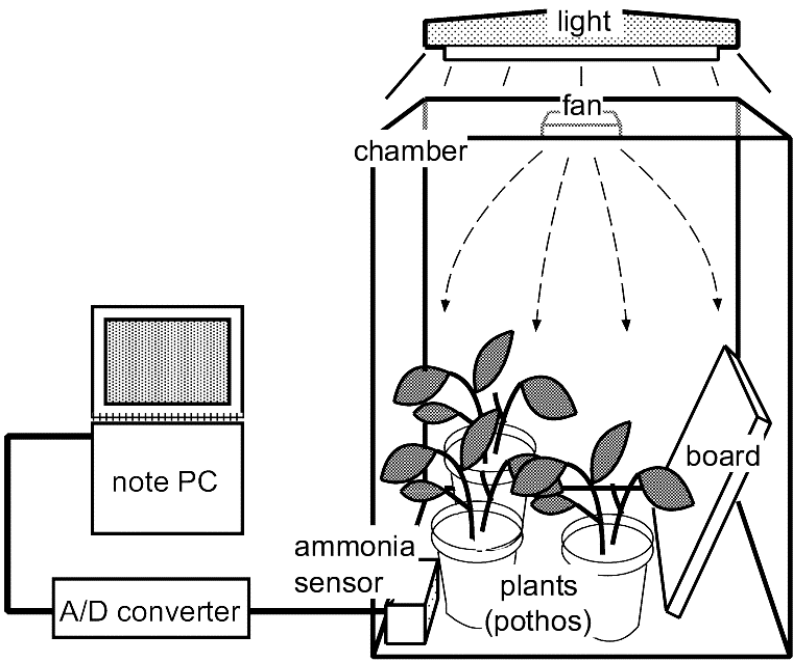

Figure 1: Measurement system. 


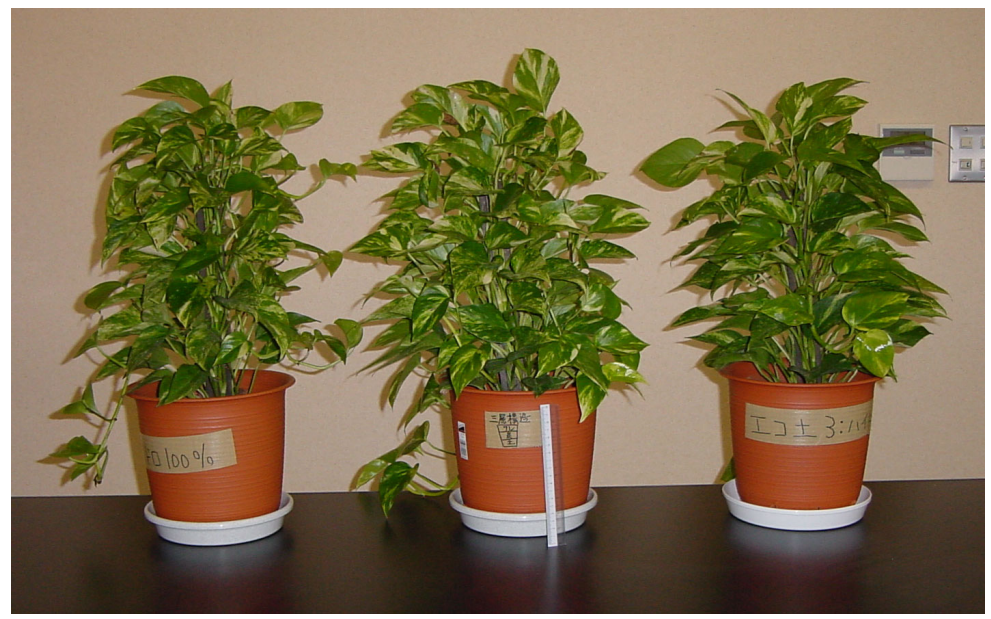

Figure 2: $\quad$ Photograph of three potted plants used in this study.

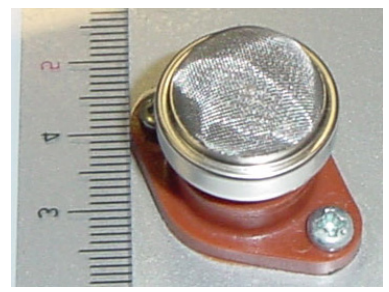

Figure 3: $\quad$ Photograph of the sensor adapted in this study.

\section{Results}

\subsection{Plant purification-characteristics}

The correlation between the gas sensor output $(V)$ and formaldehyde concentration $(C)$ can be expressed using the following equation.

$$
C=\exp [(V-2.61) / 0.474]
$$

The purification characteristics of potted pothos are shown in Fig.4. The concentration is indicated using the unit of $\left(\mathrm{mg} / \mathrm{m}^{3}\right)$ in the figure. The characteristic (a) was measured when only plywood was put in the chamber. The (b) means the characteristic when plywood and one potted pothos were installed. It reaches a maximum value after about eight hours from the beginning of the experiment and the concentration is about $0.3 \mathrm{mg} / \mathrm{m}^{3}$ after 24 hours. The level in (a) is $0.67 \mathrm{mg} / \mathrm{m}^{3}$. The maximum value of (b) is $0.34 \mathrm{mg} / \mathrm{m}^{3}$. The characteristic

(c) means the case when two pothos pots were inserted with the plywood. The maximum concentration $\left(C_{\max }\right)$, the time $\left(t_{\max }\right)$ at which the characteristic reached 
$C_{\max }$ and $C_{24}$ which means the concentration after 24 hours are also examined. In (c), $C_{\max }$ is $0.217 \mathrm{mg} / \mathrm{m}^{3}, t_{\max }$ is 3 hours and $C_{24}$ is $0.15 \mathrm{mg} / \mathrm{m}^{3}$. In characteristic (d), $C_{\max }$ is $0.18 \mathrm{mg} / \mathrm{m}^{3}, t_{\max }$ is 2 hours and $C_{24}$ is $0.1153 \mathrm{mg} / \mathrm{m}^{3}$. These values are shown in Fig.5. $C_{24}, t_{\max }$ and $C_{\max }$ decrease as the number of pot $(n)$ increases. The relationship between $C_{24}$ and $n$ can be expressed using the eq. (4). The $C_{24}$ does not decrease largely if the number of pots increases over 4 . The concentration $\left(C_{0}\right)$ in the thermo-hygrostat room was about $0.108 \mathrm{mg} / \mathrm{m}^{3}$. When $n$ is greater than 4 , the concentration can be controlled below $C_{0}$ which is considered the outside concentration of the chamber.

$$
C_{24}=0.59 \exp (-n)+0.08
$$

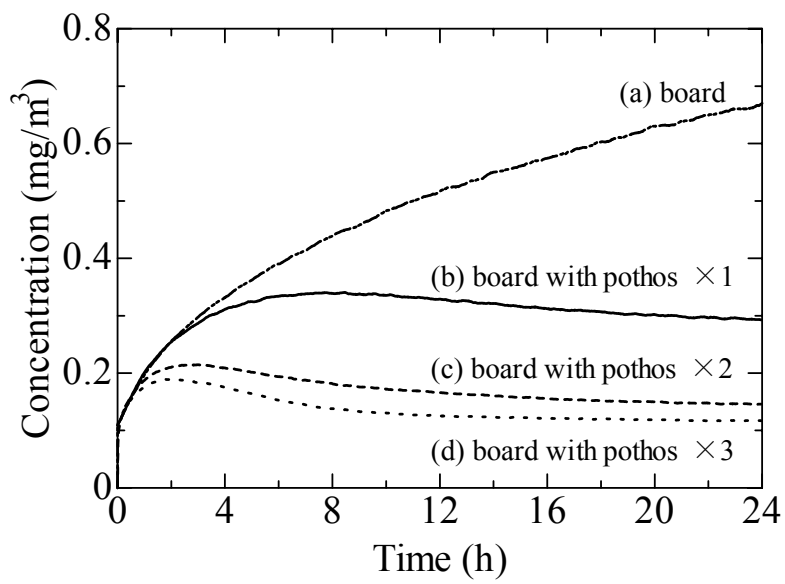

Figure 4: $\quad$ Sensor outputs for a building board.



Figure 5: The characteristics of $C_{\max }, C_{24}$ and $t_{\max }$ as a function of the number of pots. 


\subsection{Simulation for plant purification-capability}

It is possible to derive the relationship between the formaldehyde concentration $\left(C(t)\left(\mathrm{mg} / \mathrm{m}^{3}\right)\right)$ in the chamber and the emission volume per hour $E(t)\left(\mathrm{mg} / \mathrm{m}^{3}\right)$ from the characteristic (a) in Fig.4. It is indicated in eq.(5). In the equation, $t$ means time $(h)$ and $\Delta C(t)$ means the variation concentration for $\Delta t . V_{0}\left(\mathrm{~m}^{3}\right)$ means the cubic volume of the chamber which is 200 liters.

$$
E(t)=\Delta C(t) \times V_{0} / \Delta t
$$

The result when eq.(5) is applied to the characteristic (a), is shown in Fig.6. It is obvious that the emission volume of formaldehyde from the plywood decreases as the concentration in the chamber increases. The approximate function of $E(t)$ and $C(t)$ which is introduced in Fig.6, is expressed in eq.(6).

$$
E(t)=0.0418 \exp [-6.53 C(t)]+0.0019
$$

First, the concentrations in each plot of the characteristics (b), (c) and (d) in Fig.4 are derived, the values are substituted for the eq.(6). The $E(t) \mathrm{s}$ for (b), (c) and (d) can be obtained. The $E(t)$ can be also expressed as eq.(7) using the plant purification volume $P(t)(\mathrm{mg})$ and the formaldehyde concentration change $C_{v}(t)(\mathrm{mg} / \mathrm{h})$.

$$
P(t)=E(t)-C_{v}(t)
$$

$E(t), P(t)$ and $C_{v}(t)$ characteristics for three pothos pots are shown in Fig.7. $P(t)$ increases with the passage of time. $E(t)$ decreases at a time and increases after that. The difference between $E(t)$ and $P(t)$ is $C_{v}(t)$. $E(t)$ and $P(t)$ take almost same value after 12 hours, namely emission volume and purification volume by plant are nearly equal. Therefore, $C_{v}(t)$ is nearly zero after 12 hours.

Total purification volume of three pothos pots for a day is about $0.46 \mathrm{mg} /$ day according to the $P(t)$ characteristic in Fig.7. Similarly, the values for two pots and one pot are $0.37 \mathrm{mg} / \mathrm{day}$ and $0.16 \mathrm{mg} /$ day. Mean plant purification volume for a day and a pot is about $0.165 \mathrm{mg} /($ day $\times$ pot). The purification volume $P(t)$ for the number of pots $(n)$ is derived and the relationship can be expressed using the eq.(8). We can simulate the $P(t)$ for $n$ using eq.(8).

$$
P(t)=\alpha(1-\exp (-\beta t))
$$

where

$$
\begin{gathered}
\alpha=0.0031(1-\exp (-0.344 n)) \\
\beta=0.886(1-\exp (-0.534 n))
\end{gathered}
$$

We can also estimate the concentration variation of formaldehyde as a function of time using the derived equations. Namely, the emission volume $E(t)$ 
can be introduced using the formaldehyde concentration at $t(h)$. The initial concentration $\left(C_{0}\right)$ was in the thermo-hygrostat room. $C_{0}=0.108 \mathrm{mg} / \mathrm{m}^{3}$. The $C_{v}(t)$ can be also introduced using the values of $E(t)$ and $P(t)$ in eq.(7). This $C_{v}(t)$ is added in every $t(h)$ successively and the concentration-variation as a function of time can be estimated accurately. The estimated results are shown in Fig.8. The number of pots $(n)$ is adopted as a parameter in the figure. The figure is very similar to Fig.4. The estimated concentrations for $n=4$ and 5 become lower than the value of outside $\left(C_{0}\right)$ after 24 hours. This result is almost equal to the result of Fig.5.

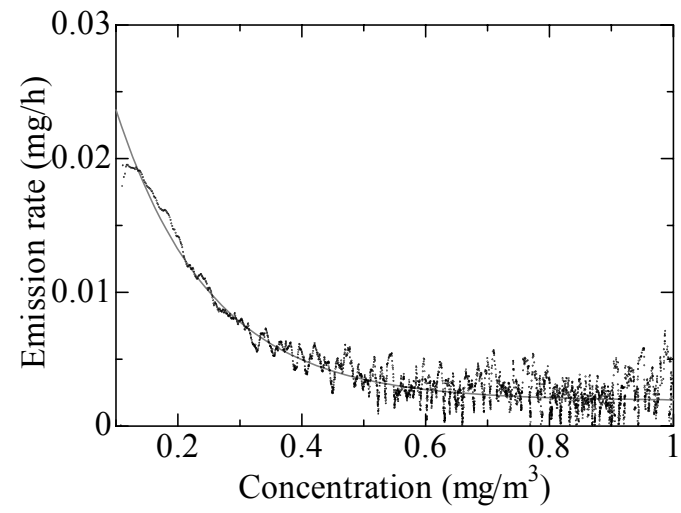

Figure 6: Formaldehyde emission rate vs. concentration in the chamber.

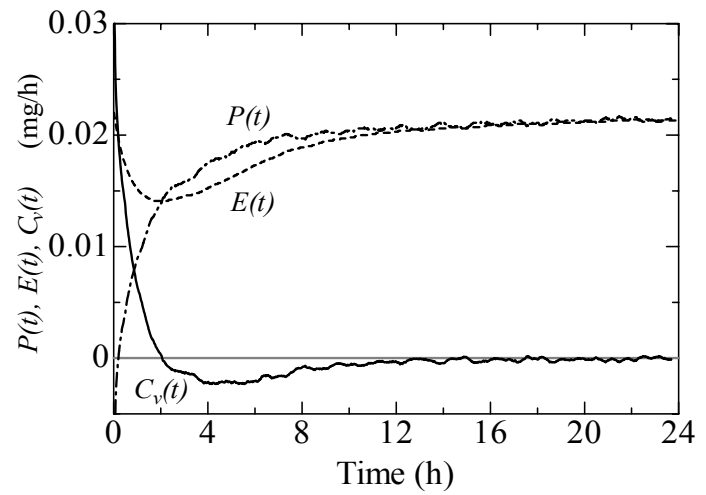

Figure 7: $\quad P(t), E(t), C_{v}(t)$ as a function of time. 


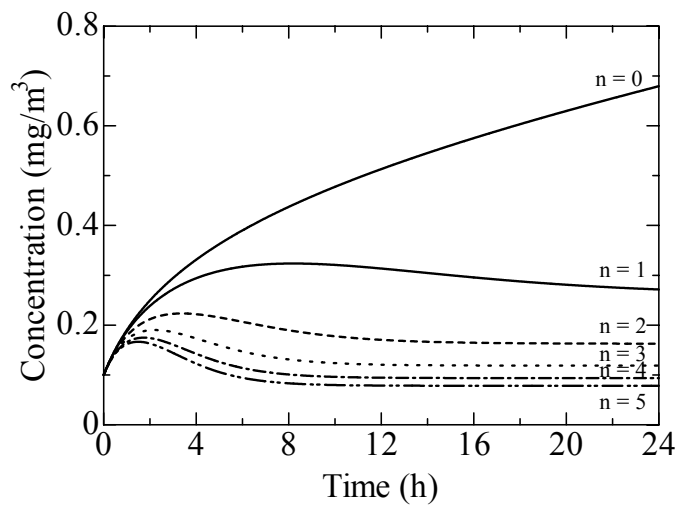

Figure 8: Estimation of formaldehyde concentration as a function of time.

\section{Conclusions}

The purification processes of plants for formaldehyde, which generates from a piece of plywood, are examined. The potted pothos is adopted as a subject. It is shown quantitatively that the emission volume from the plywood decreases as the atmospheric concentration increases. It also became obvious that the formaldehyde concentration decreased by increasing the number of pots. The total purification volume could not increase by a simulation even if the number of pots exceeded a threshold value. The value was four in this experiment. The optimum number of pots in various types of indoor environment can be derived on the basis of these results.

The influence of ventilation must be also considered in the future.

\section{References}

[1] Oyabu, T., Onodera, T., \& Takenaka, K., Purification Capability of Potted Plants for Removing Atmospheric Formaldehyde. Proc. of 5th Int. Conf. on Engineering Design and Automation, Las Vegas, USA, pp.1080-1085, 2001.

[2] Oyabu, T., Onodera, T., Kimura, H., \& Sadaoka, Y., Purification Ability of Interior Plant for Removing of Indoor-Air Polluting Chemicals Using a Tin Oxide Gas Sensor. J. Jpn. Soc. Atmos. Environ., 36(6), pp.319-325, 2001.

[3] Oyabu, T., Takenaka, K., Onodera, T., \& Nanto H., Purification Ability of a Potted Plant and Soil for Atmospheric Gasoline. Proc. of 1st Int. Congress on Petroleum Contaminated Soils, Sediments, and Water, London, UK, p.117, 2001.

[4] Oyabu, T., Sawada, A., Onodera, T., Takenaka, K. \& Wolverton B. C., Characteristics of Potted Plant for Removing Offensive Odors. Sensors and Actuators B, 89, pp.131-136, 2003.

[5] Wolverton, B. C., How to grow fresh air, Penguin Books: New York, 1996. 
[6] Wolverton, B. C. \& Wolverton, J. D., Plants and Soil Microorganism: Removal of Formaldehyde, Xylene, and Ammonia from the Indoor Environment. J. Missil. Acad. Sci., 38(2), pp.11-15, 1993.

[7] Oyabu, T., Sensing characteristics of $\mathrm{SnO} 2$ thin film gas sensor. J. Appl. Phys., 53(4), pp.2785-2787, 1982.

[8] Oyabu, T., Osawa, T., \& Kurobe, T., Sensing characteristics of tin oxide thick film gas sensor. J. Appl. Phys., 53(11), pp.7125-7130, 1982. 